Time to review authorisation and funding for new cancer medicines in Europe? Inferences from the case study with olaratumab.

(Running header: Experience and implications with olaratumab)

Caridad Pontes ${ }^{* 1,2}$, Corinne Zara ${ }^{1}$, Torrent $\mathrm{J}^{1}$, Merce Obach ${ }^{1}$, Cristina Nadal ${ }^{3}$, Patricia Vella Bonanno ${ }^{4}$, Michael Ermisch $^{5}$, Steven Simoens ${ }^{6}$, Renata Curi Hauegen ${ }^{7}$, Jolanta Gulbinovic ${ }^{8}$, Angela Timoney ${ }^{4,9}$, Antony P Martin ${ }^{10}$, Tanja Mueller ${ }^{4}$, Anna Nachtnebel ${ }^{11}$, Stephen Campbell ${ }^{12,13}$, Gisbert Selke ${ }^{14}$, Tomasz Bochenek ${ }^{15}$, Celia C Rothe $^{15}$, Ileana Mardare ${ }^{16}$, Marion Bennie ${ }^{4}$, Jurij Fürst ${ }^{17}$, Rickard E Malmstrom ${ }^{18}$, Brian Godman ${ }^{4,10,19,20}$

${ }^{1}$ Drug Area, Catalan Health Service, Travessera de les Corts 131, Edifici Olimpia, 08028 Barcelona, Spain. Email: cpontes@catsalut.cat,czara@catsalut.cat; mobach@catsalut.cat,jtorrent@catsalut.cat ${ }^{2}$ Department of Pharmacology, Therapeutics and Toxicology, Universitat Autònoma de Barcelona, Barcelona, Spain

${ }^{3}$ Health Care Unit Director, Catalan Health Service, Barcelona, Spain: Email: cnadal@ catsalut.cat ${ }^{4}$ Strathclyde Institute of Pharmacy and Biomedical Sciences, University of Strathclyde, Glasgow G4 0RE, United Kingdom. Email: Brian.godman@strath.ac.uk; patricia.vella-bonanno@strath.ac.uk; tanja.muller@strath.ac.uk; marrion.bennie@strath.ac.uk ${ }^{5}$ Pharmaceutical Department, National Association of Statutory Health Insurance Funds, Berlin, Germany. Email: Michael.Ermisch@gkv-spitzenverband.de

${ }^{6} \mathrm{KU}$ Leuven Department of Pharmaceutical and Pharmacological Sciences, Leuven, Belgium. Email: steven.simoens@kuleuven.be

${ }^{7}$ National Institute of Science and Technology for ${ }^{7}$ Innovation on Diseases of Neglected Populations (INCTIDPN), Center for Technological Development in Health (CDTS), Osvaldo Cruz Foundation (Fiocruz), Rio de Janeiro, Rio de Janeiro, Brazil. Email: renatacuriadv@gmail.com

${ }^{8}$ Department of Pathology, Forensic Medicine and Pharmacology, Institute of Biomedical Sciences, Faculty of Medicine, Vilnius University, Vilnius, Lithuania. Email: jolanta.gulbinovic@gmail.com

${ }^{9}$ NHS Lothian Director of Pharmacy, NHS Lothian, Edinburgh, UK. Email:

angela.timoney@nhslothian.scot.nhs.uk

${ }^{10}$ Health Economics Centre, University of Liverpool Management School, Liverpool, UK. Email:

Brian.Godman@liverpool.ac.uk; a.p.martin@liverpool.ac.uk

${ }^{11}$ Hauptverband der Österreichischen Sozialversicherungsträger, Haidingergasse 1, AT-1030, Vienna, Austria. Email:Anna.Nachtnebel@ sozialversicherung.at

${ }^{12}$ Centre for Primary Care, Division of Population Health, Health Services Research and Primary Care, University of Manchester, Manchester, M13 9PL, UK. Email: stephen.campbell@ manchester.ac.uk 
${ }^{13}$ NIHR Greater Manchester Patient Safety Translational Research Centre, School of Health Sciences, University of Manchester, Manchester, UK

${ }^{14}$ Wissenschaftliches Institut der AOK (WidO), Rosenthaler Straße 31, 10178 Berlin, Germany. Email: Gisbert.Selke@wido.bv.aok.de

${ }^{15}$ Department of Drug Management, Faculty of Health Sciences, Jagiellonian University Medical College, Krakow, Poland. Email: mxbochen@cyf-kr.edu.pl; celia.rothe@outlook.de

${ }^{16}$ Faculty of Medicine, Public Health and Management Department, "Carol Davila" University of Medicine and Pharmacy Bucharest, 050463 Bucharest, Romania. Email: ileana.mardare@umfcd.ro

${ }^{17}$ Health Insurance Institute, Miklosiceva 24, SI-1507 Ljubljana, Slovenia. Email: Jurij.Furst@zzzs.si

${ }^{18}$ Department of Medicine Solna, Karolinska Institutet and Clinical Pharmacology, Karolinska University Hospital Solna, SE-171 76, Stockholm, Sweden. Email: rickard.malmstrom@ki.se

${ }^{19}$ Division of Clinical Pharmacology, Karolinska Institute, Karolinska University Hospital Huddinge, SE-141 86, Stockholm, Sweden. Email: Brian.Godman@ki.se

${ }^{20}$ School of Pharmacy, SefakoMakgatho Health Sciences University, Garankuwa, South Africa.

*Corresponding author: Dr C Pontes; Drug Area, Catalan Health Service, Travessera de les Corts 131, Edifici Olimpia, 08028 Barcelona, Spain. Telephone number: +34 934038942 Department of Pharmacology, Therapeutics and Toxicology, Universitat Autònoma de Barcelona, Barcelona, Spain

ORCID ID: 0000-0002-3274-6048

(Accepted for publication Applied Health Economics and Health Policy) 


\title{
Time to review authorisation and funding for new cancer medicines in Europe? Inferences from the case study with olaratumab
}

\begin{abstract}
The potential benefits of early patient access to new medicines in areas of high unmet medical need are recognised, but uncertainties concerning effectiveness, safety, and added value when new medicines are authorised and subsequently funded based on initial preliminary data only have important implications. In 2016, olaratumab received accelerated conditional approval from both the EMA and FDA for the treatment of soft tissue sarcoma based on the claims of a substantial reduction in the risk of death with an 11.8 month improvement in median overall survival in a phase II trial in combination with doxorubicin versus doxorubicin alone. The failure to confirm these benefits in the post authorisation pivotal trial has highlighted key concerns regarding early access and conditional approvals for new medicines. Concerns include potentially considerable opportunity clinical and economical costs, so that patients may have received suboptimal treatment and money spent has foregone the opportunity to improve access to effective treatments. As a result, it seems reasonable to reconsider current marketing authorisation models and approaches. Potential ways forward include closer collaboration between regulators, pharmaceutical companies and payers to enhance the generation of rapid and comparative confirmatory trials in a safe and fair way with minimal patient exposure to achieve robust evidence. Also, it may be time to review early access systems and to explore new avenues regarding who should pay or part pay for new treatments whilst information is being collected as part of any obligations for conditional marketing authorisation. Greater co-operation between countries regarding the collection of data in routine clinical care, and further research on post marketing data analysis and interpretation, may also contribute to improved appraisal and continued access to new innovative cancer treatments.
\end{abstract}

\section{Key points for decision makers:}

- Recently, a medicine for cancer that was conditionally approved in 2016 on the basis of preliminary data was withdrawn from the market, after failing to confirm efficacy.

- Early patient access to new medicines in areas of high unmet medical need may be justified on ethical reasons based on the possibility of added benefit but assumes uncertainty

- Uncertainty may though negatively impact on public health and may deviate resources from more effective interventions.

- There is an urgent need to reconsider current mechanisms regulating early access to innovative medicines with substantial uncertainty.

Key words: olaratumab, conditional reimbursement, managed entry agreements, new models, patient level data

\section{Introduction}

Expenditure on medicines is expected to have a constant growth, driven by high priced innovation, aging of populations, a wider role of medicines in prevention of non-communicable diseases and improved identification of potentially treatable patients through information technology (IT) systems $(1,2)$. Oncology treatments and 
orphan drugs currently lead the growth, which is favoured by single disease model guidelines and policies (3-5). However, the continual launch of new high-priced medicines among European countries with finite budgets and faced with providing, or seeking to provide, universal healthcare for their citizens is putting additional strain on their healthcare systems $(5,6)$. This needs to be addressed without compromising care.

There is a growing focus on cancer treatments across countries in view of increasing incidence and prevalence rates as well as current and projected high expenditures. Currently there are 18.1 million new cancer cases annually worldwide, which is likely to reach 21.4 million per year by 2030 (7-9). In addition, prices for new cancer medicines are usually high, often with limited correlation with their level of health gain (7, 10-15), aided by the emotive nature of this disease area $(13,16,17)$. There is a similar situation for new medicines for orphan diseases (18-21). The regulations regarding drug pricing in Europe are diverse $(6,22)$, and it is difficult to have pan European figures. However, the average cost per patient of a new orally administered cancer medicine in the United States of America (USA) typically exceeded \$135,000 a year in 2014, up to six times higher than prices in the early 2000s after adjusting for inflation $(15,23)$. These combined factors resulted in world-wide sales of medicines for oncology at $\$ 107$ billion in 2015, an increase of $11.4 \%$ since 2014, and $\$ 133$ billion in 2017, with an estimated $\$ 200$ billion by 2022 (24). As a result, expenditures on medicines for cancer now dominate pharmaceutical expenditure in developed markets $(5,9,24-26)$. This will continue with over 500 companies actively pursuing new oncology medicines in over 600 indications $(5,25)$ with envisaged high price expectations $(11,16,23,27)$. Consequently, discussions over prices and affordability of new cancer medicines will continue especially with greater knowledge regarding their actual cost of goods (28-36).

On the other hand, there continues to be unmet need for new medicines for cancer with currently 9.6 million cancer deaths annually and rising across the world $(6,9,37)$. As a result, there is a wish among various stakeholders to see new promising cancer medicines being made available, funded, and prescribed as early as possible through a variety of initiatives (38-44). Regulatory initiatives in Europe to address this include special programs aimed at identifying potentially breakthrough therapies deserving priority assessment and/or to allow early authorization through adaptive licensing conditional of compliance with the requirements as part of the conditional marketing authorisation $(41,45,46)$. Nevertheless, while early access is the obvious response to an urgent clinical need, the potential benefits of early access need to be balanced against the risk of medicines being introduced too early into routine clinical practice with only limited evidence on their effectiveness and safety. The focus on early access to cancer drugs has led to a higher failure rate of translating promising Phase II into positive findings in Phase III and beyond, as compared to other disease areas (47-51). Failure to improve survival in practice despite surrogate markers looking promising will represent lost clinical opportunities for patients and wasted resources for healthcare systems $(13,52)$. Besides, the effectiveness of new medicines in clinical settings may be compromised by patients being older, having greater heterogeneity, and having a greater number of co-morbidities than those enrolled into phase III clinical trials, further impacting on the possible added value of new drugs $(4,53,54)$. This is besides statistical uncertainties in trial results that occur due to current methodological limitations (55).

To help address these challenges, a number of initiatives have been proposed across Europe to fund new premium priced medicines in a sustainable way. These include general measures to save money for healthcare systems such as encouraging increased prescribing of low cost generics and biosimilars without compromising 
care, with biosimilars priced as low as $30 \%$ of originators, which has resulted in aggressive lowering of the prices of originator biological in some European countries $(36,56-59)$. In addition, new models have been developed across Europe to improve the managed entry of new premium priced medicines. Health authority activities in these models start with horizon scanning and budgeting activities up to three years before potential marketing authorisation, with monitoring activities continuing post launch to assess the effectiveness, safety and value of new medicines in routine clinical care $(6,59-63)$. New models have also been proposed among European and other countries to address concerns with increased prices for new medicines including valuebased pricing and multi-criteria decision analyses, the latter aimed particularly at new medicines for rare diseases $(3,64-67)$.

In Europe, as well as other regions, Managed Entry Agreements (MEAs) are also increasingly included as part of reimbursement and funding considerations to address issues of prices and affordability of new medicines (68$73)$, especially for new medicines for cancer, orphan diseases and advanced therapies $(23,70,74,75)$. Some European healthcare systems have also contemplated the possibility of introducing conditional reimbursement schemes for new medicines whose benefits are largely unknown at the time of marketing authorisation. Other actions include the co-operation of key stakeholders, including oncologists and health authority personnel, working together to agree minimum effectiveness thresholds for funding new cancer medicines at premium prices $(6,76,77)$. Alongside this, agreeing on likely patient numbers and target populations for new cancer medicines to help keep costs within allocated budgets (59).

However, despite recent publications suggesting increasing interest as well as the growing use of both financial and outcome based MEAs $(68,72,73,78-81)$, the number of outcome based schemes globally appear to have plateaued in recent years (71). This is perhaps not surprising since in practice there are a number of issues and challenges with outcome based schemes $(38,39,82,83)$. These include insufficient scientific data being generated to reach robust conclusions, a lack of IT infrastructures and manpower to monitor the effectiveness and safety of new medicines in routine care, new medicines not being taken off reimbursement lists (delisted) despite limited value in practice, and MEAs just monitoring that prescribing is appropriate according to agreed protocols rather than actually assessing outcomes in practice $(5,69,79,82,84)$. In addition, such schemes may not be sufficient to contain the cost of those medicines that confer real benefits to patients resulting in a budget impact that could still be unsustainable for health care systems (85). As a result, there is a need to re-look at current mechanisms from a payers' perspective that encourages innovation in a sustainable way but mindful of potential risks for patients.

Consequently, the aim of this Current Opinion article is to discuss the benefits, risks and challenges involved in granting early access to premium-priced new medicines in areas of unmet medical need, and illustrate these with the recent case of olaratumab (Lartruvo ${ }^{\circledR}$, Eli Lilly) in the treatment of metastatic soft tissue sarcoma (STS). Potential ways forward to authorise and fund such medicines in the future are proposed given the issues raised by olaratumab. 


\section{The olaratumab case and its implications}

The recent failure of the post authorisation pivotal trial of olaratumab in the treatment of metastatic soft tissue sarcoma (STS) $(86,87)$ has confirmed concerns previously expressed regarding early access and conditional approvals for new medicines $(40,41,69,88)$.

Olaratumab is an antagonist of the platelet derived growth factor receptor- $\alpha$ (PDGFR- $\alpha$ ) expressed on tumour and stromal cells (89). Olaratumab received an orphan designation for STS, and was conditionally approved in Europe by the European Medicines Agency (EMA) after an accelerated assessment in September 2016. Approval was based on the results of a single phase II study involving 133 adults with advanced STS (90). The trial showed a limited effect on the primary endpoint of progression-free survival (PFS) for olaratumab in combination with doxorubicin compared to doxorubicin alone (median of 6.6 months versus 4.1 months; Hazard Ratio (HR) 0.67; 95\% CI, 0.44-1.02; $\mathrm{p}=0.0615$ ); however, differences in favour of olaratumab were shown for the secondary endpoint of overall survival (OS) (median OS 26.5 months versus 14.7 months; HR 0.46; 95\% CI, 0.30-0.71; $\mathrm{p}=0 \cdot 0003)(86,90,91)$. European central marketing authorisation (through EMA evaluation) was granted conditioned on the completion of an on-going confirmatory phase III trial (92). Similarly, the Food and Drug Administration (FDA) granted the olaratumab application a fast track designation, a breakthrough therapy designation and a priority review status, because of the preliminary clinical evidence, with an accelerated marketing authorisation issued in the US in October 2016 (93).

However, in January 2019, preliminary results from the confirmatory study failed to confirm any benefit of olaratumab with doxorubicin as compared with placebo and doxorubicin in the overall survival of patients with STS (median OS 20.4 vs 19.8 months (HR=1.05, 95\% CI: 0.84-1.30; $p=0.69$ ). Also, lower PFS was observed with olaratumab (5.4 vs $6.8 \mathrm{~m}$; HR=1.23, 95\%CI: $1.01-1.50$; p = 0.04) (94). As a consequence, both the EMA and the FDA issued a notification recommending that no new patients with STS should be started on treatment with olaratumab. Existing patients should consult with their physician if they are receiving benefit from olaratumab $(95,96)$.

It is estimated that overall approximately one thousand patients had been treated with olaratumab in the European Union by the time the phase III results became known (95), although actual figures may be higher. This represents considerable expenditures among a number of European health authorities. For instance by the end of January 2019, olaratumab had been prescribed to approximately 80 patients in Catalonia, Spain, which at a cost of approximately $€ 30,000$ /patient, resulted in expenditures of over $€ 2$ million.

The concerns with olaratumab are first and foremost in terms of wasted time from the possibility of starting alternative treatments which could have been more effective, as well as potential adverse events suffered by patients due to olaratumab. Secondly, as mentioned, there are opportunity costs, denying funding for alternative treatments to the same patients or other patients in national healthcare systems. No healthcare system has infinite resources available and all need to invest in treatments that truly offer health gain for patients to optimise overall health for all within available resources.

It is acknowledged that the process of drug-development and evidence generation continues throughout the medicine's life-cycle and does not stop with marketing authorisation $(3,5,6)$. In addition, the marketing authorisation of new medicines is almost always associated with some degree of uncertainty, with only a limited 
amount of clinical data generally available at launch since clinical trials typically include only highly selected patients $(4,97)$. However, ethical issues arise when a positive effect for a new medicine has been shown during clinical development. Early regulatory access is generally demanded when new promising medicines potentially offer life-saving opportunities to patients who may not have survived until the full clinical trial data is accrued $(54,98,99)$. However early access may also lead to ethical concerns, because treatments of uncertain risk/benefit ratio may be used precisely on those patients who are at most need and vulnerable, and in this sense a highly restrictive policy in granting conditional approvals should be the rule particularly when alternative and potentially more effective treatments could have been given. This is especially the case with cancer medicines based on preliminary findings (47).

The mismatch between the need for robust scientific evidence for decision making and the facilitation of early access to potentially life-saving treatments may result in considerable dilemmas not only for regulators, but especially for health authorities responsible for funding new premium priced medicines. Applicant companies argue that the new medicine deserves a high price as it may address a significant current unmet need. This is because a conditional authorisation should only be granted if the new medicine shows high clinical value. On the other hand, pricing and reimbursement authorities deciding on subsequent prices and funding argue that the incompleteness of data represents risks and thus a lower value. Issues such as equity, allocation of healthcare resources, prioritisation of limited budgets and opportunity costs need to be carefully considered alongside uncertainties in the clinical data $(40,43,88,100)$. However, negotiations in practice may also be influenced by many stakeholders including clinicians and scientific societies, industry lobbies, politicians, lay media and patient associations, as well as market considerations of the individual healthcare system.

Flexibility regarding conventional regulatory requirements has been widely implemented by regulators, especially in diseases of low prevalence and advanced therapies including gene therapies. An example is that only 38 out of 125 (30\%) orphan medicinal products authorisations granted by the EMA up to December 2014, including both oncological and non-oncological products, were based on replicated pivotal trials. Authorisations included 159 pivotal trials, of which 53 did not include a control arm, 50 did not use randomisation, 75 were open-label, and 119 used intermediate or surrogate variables as their main outcome measure (101). Similar results have been seen with FDA authorisations of oncological drugs, e.g. 7 out of 14 new oncology drugs approved in 2017 by the FDA were based on data from a phase II trial, and 3 more were based on phase I/II trials only (8). Personalised medicine is bringing new challenges as regards to the amount and type of data available at the time of drug approval (102), and basket trials including several types of tumours sharing a given biomarker may lead to agnostic authorizations, whereby the new medicine can be used in different diseases provided that the presence of the biomarker is proven will also present new challenges. Recently, the FDA granted accelerated approval for larotrectinib for adults and children with solid tumours with neurotrophic receptor tyrosine kinase gene fusion without a known acquired resistance mutation on the basis of effectiveness data from a basket trial in just 55 patients with 12 cancer types, putting pressure on other authorities (103). Although the regulation states that patients requiring orphan medicinal products deserve the same degree of evidence as those with more prevalent diseases, recognition of the difficulties in conducting standard trials in small populations together with the incentives for developing new medicines for orphan diseases, including longer patent protection, have increasingly resulted in small trials being the only basis for many dossiers for new applicants in recent years $(54,98,99)$. 
This trend is a concern since after a mean of 5.4 years post authorisation, up to $47 \%$ of oncological medicines authorised through the EMA centralised procedure still lacked data on overall survival and/or quality of life (104). In addition, of the 30 conditional authorisations granted between 2006 and 2016 by EMA, whilst 11 (37\%) have been converted into "standard" (non-conditional) marketing authorisations and 2 have been withdrawn for commercial reasons, the remaining 17 (57\%) are still conditional (105). This though has to be balanced against the fact that in 2017 new drug approvals in Europe had a median time between patent filing and marketing authorisation of 14 years, although faster than previously (24).

Whilst early access schemes, including the European proposal for Medicines Adaptive Pathways to Patients (MAPPs) scheme $(41,97)$, may satisfy both patients' and professionals' needs for rapid access to new potentially innovative medicines, they do so at the expense of postponing final decisions about the effectiveness of new treatments until uncertainty is reduced (106). This may have negative consequences for patients. Initiatives such as the English Cancer Drug Fund (107) which prioritised treatment of cancers over those for other disease conditions, and in such situations the opportunity cost for patients who were not prioritised are even greater.

Regulatory requirements of replicates of clinical results in different populations are intended to minimise the risk for false positives. Consequently, they are intended as a strong measure to protect the public from the risks associated with authorisation of ineffective and unsafe treatments $(108,109)$. Alongside this, once a new medicine is on the market and reimbursed, it may be difficult to recruit patients into ongoing clinical trials because patients may well be reluctant to randomization if they may access the newly commercialized product (106). When treatments are authorised with conditions that include post-marketing clinical trials, it may be the case that trials are unfeasible or they may have to be stopped due to recruitment failure. Consequently, only uncontrolled observational studies with treatments commercially supplied and paid for by healthcare systems become a potential viable option. Observational trials might be prospectively designed and sponsored by companies; however, administrative databases and electronic clinical records may be the source for effectiveness studies of new medicines (110-112).

This may potentially be against the interests of patients and of healthcare systems because the quality of evidence from observational studies will be lower than that obtained by randomised trials, and it can be difficult to conclude on actual effectiveness especially if there is a heterogeneous population. In addition, healthcare expenditure on medicines with uncertain efficacy or safety may have relevant opportunity costs for other patients who happen to have a different diagnosis or who happen to have a disease condition where there is less motivation to prioritise treatment. Finally, paying for treatments which are potentially ineffective or unsafe until more data becomes available shifts the financial and other burdens from pharmaceutical companies onto national health services. This issue needs urgent consideration especially in equity-based healthcare systems.

There are also concerns among health authorities that early approval decisions based on preliminary data may be interpreted by physicians and others as reflecting proven improvements in efficacy compared to current standards of care, or adequately addressing the lack of treatment options (8). This may turn out to be wrong as more data becomes available. Consequently, there is a risk that key stakeholder groups may overestimate the effects of new medicines compared with those potentially seen in routine clinical practice, providing false hope 
and enhancing the use of such medicines to the detriment of current standards of care and typically at a higher financial cost $(113,114)$.

It would be logical to consider that if the assumptions on benefit/risk made at the time of authorisation are not met, or if the conditions are not fulfilled, the guarantees commensurate with marketing authorisation are compromised, and as a result authorisation should be suspended. However, this is not always the case as seen with medicines for orphan diseases in the Netherlands $(20,38)$. Even though the reversibility of authorisation should be the basic axiom of any adaptive licensing or conditional approval process, there can be concerns and issues in practice that make authorisation reversal difficult even if the effectiveness and/ or value of a new medicine is not met in clinical practice. This can be due to a number of reasons including pressure from patients and other stakeholders to keep the medicine on the market $(5,20,115,116)$. Once on the market, the new treatment may be rapidly adopted as the standard of care particularly if the principal basis for approval is unmet medical need, especially if the benefits are over-estimated. This is also a concern. Patients on treatment may require continuation at an individual level, and interruption of ongoing treatments may represent a major ethical issue unless a new serious risk is identified and unbalances the original benefit/risk evaluation on which the marketing authorisation was based. This also needs to be addressed.

If clinical trial results are clear enough to suspend treatments, such as a null benefit or identification of new safety issues, the clinical value should be reconsidered and advice issued to change future prescribing. This has happened in the case of olaratumab $(86,95)$. Nevertheless, failure to meet agreed effectiveness criteria with conditional schemes has not always led to a suspension of marketing authorisation and funding agreements (20, 38). There may in part be clinical reasons to maintain a new medicine on the market even when the expected benefits are not met in clinical practice. However, reimbursement and funding decisions must be reviewed to adjust for a lower proven value in practice so that health authorities are not paying higher prices for new treatments that turn out to have similar or lower effectiveness than current treatments. In reality though, it can be challenging to modify prices (or discounts) and/ or delist new medicines based on a lower proven value in routine care especially in emotive disease areas $(5,38)$.

\section{Potential ways forward}

A fast-track authorization based on early promising results to address areas of unmet medical need might be regarded as implicitly recognizing not only a favourable risk/benefit, but also that the new medicine has a high intrinsic value despite considerable uncertainty. Such assumptions are typically used to support manufacturers' requests for premium prices during reimbursement negotiations despite incomplete data (106). However, conceptually, a conditional approval with a lower level of evidence and greater uncertainty should be reflected in lower prices during the data gathering period particularly since the costs of evidence generation as well as the costs of therapy are likely to be transferred from pharmaceutical companies to other key stakeholders including healthcare authorities. In addition, often observational studies are conducted for example by health care providers themselves or research institutes, including universities, independently from (and without support of) the manufacturer of the new medicine in question to augment insufficient and/or immature data emerging from clinical trials $(41,69)$. This also needs to be reflected in potential prices. 
We are aware that conditional marketing authorisation has the same legal status as 'standard' non-conditional marketing authorisation. Consequently, and as required by the European Commission's Transparency Directive (Council Directive 89/105/EEC), health care services need to enter into reimbursement negotiations (117).

Concurrently, the marketing authorisation holders should generate the evidence in line with the requirements of the conditional approval. In view of this, we believe it should be the responsibility of the pertinent pharmaceutical companies to organise and pay for the generation of such data. However, this is not always enforced, and, as mentioned, not only the costs of paying for the new medicines, but also those for evidence generation, typically become the responsibility of health authorities and payers.

As a result, it has been proposed that healthcare systems should only pay for performance, i.e. for proven effectiveness, and utilise the concept of success fees rather than refunding expenditures if agreed outcomes are not reached (85). Even though in several countries the current legislative framework might allow for this, there are a number of obstacles which need to be overcome before such arrangements are widely accepted. Firstly, pharmaceutical companies may be reluctant to accept bearing more of the financial risk than usual and fear that lower prices for conditionally approved medicines may influence external price referencing $(118,119)$. Secondly, healthcare systems might decide collectively (or at least as a coalition of the willing) to repeal the current lack of transparency of prices especially confidential discounts associated with early approval schemes $(6,19)$. This builds on recent United Nations initiatives to improve access to medicines $(120,121)$. However, currently healthcare systems find themselves in a prisoners' dilemma thinking they are getting a better price compared to other countries, with pharmaceutical companies favouring the current lack of transparency allegedly due to the possibility of adjusting prices to individual health systems' capacities (122). Thirdly, in the case of new cancer medicines, evidence generation now typically includes data on possible biomarkers given the heterogeneity of different tumours $(24,123)$. However, even with or for stratified or personal medicines with the use of biomarkers, there can still be considerable uncertainty whether an individual patient responds to a given treatment.

If MEAs are based on payment of successful cases only, this may mean in reality a smaller market for pharmaceutical companies than originally envisaged. Companies might wish this to be reflected in higher agreed initial prices (124). However, such considerations typically do not apply to new cancer medicines where pharmaceutical companies generally extend the indications over the lifecycle of the medicine without necessarily reducing their prices as the number of patients accrues. This was seen for instance with imatinib which was initially launched at a high price as a medicine for orphan diseases but reached blockbuster status with new indications achieving total sales of over US\$4.2billion in 2012 alone (125, 126). Extending the indications for trastuzumab resulted for instance in worldwide sales of US\$6.79billion in 2015, with the combination with emtansine further extending its patent life following the availability of biosimilars for trastuzumab alone $(3,127-129)$. Caution is also needed with outcome based MEAs given the current lack of capacity to routinely collect patient level data among a number of European countries.

Another solution could be different approaches for the funding new medicines. Possible approaches could include de-linking research and development (R\&D) from subsequent commercialisation, especially given the opacity of actual costs and the extent of R\&D for new medicines already undertaken in universities as well as 
publicly funded R\&D (116, 130-132). In any event, it should be remembered that the public health care budget in countries with universal healthcare systems is intended to support effective interventions that improve patients' quantity and quality of life, and the limited resources need to be carefully invested to guarantee the systems' sustainability and the maximisation of benefits for all patients.

We do recognise that observational patient level studies including disease and/or drug registries have, for instance, enhanced our understanding regarding the risks and benefits of biological medicines in patients with rheumatoid arthritis and psoriasis, demonstrated the continued effectiveness of second-generation direct-acting antivirals in patients with hepatitis $\mathrm{C}$, illustrated differences in effectiveness and safety between medicines in a class when deciding treatment approaches, and demonstrated differences in adherence rates for new medicines in clinical practice $(110,111,133-138)$. However, whilst the IT infrastructure of health systems in many countries is improving in line with recent technical developments, there are still considerable concerns including legal concerns among European countries (139).

In those countries that are able to use patient level data for research purposes, the use of such data could be expanded to accelerate evaluating the benefits of recently approved medicines, including those with conditional approval, in actual care in order to aid treatment and funding decisions. In particular, combining data sets with pertinent data from different countries could appreciably improve our ability to conduct post-approval observational studies by tackling the major challenge of insufficient patient numbers when using registries to evaluate the cost-effectiveness of different treatment options in routine care (54). However, this will necessitate an agreement of minimum standards for collecting clinical data to support funding decisions between relevant countries (140). This will also require addressing current issues regarding the heterogeneity of data sources, often insufficient data quality (with regards to accuracy, reliability, and completeness), and opaque access to data $(54,141-143)$. The lack of availability of relevant observational data, along with its potentially poor quality, rooted in, for example, the use of legacy systems, inadequate training on system use, or the original purpose of databases, e.g. administrative rather than for clinical use, currently remains the greatest obstacle to implementing schemes requiring the continuous assessment of new medicines under accelerated access. If early access is granted ignoring increased uncertainty, coupled with the increased risk of false positive decisions with early data, we believe it is necessary to at least simultaneously gather data that enables robust conclusions with regards to the clinical effectiveness of new medicines and, ultimately, their health benefits in real life. Such concerns need to be taken forward by the European Commission as part of future developments in healthcare.

However, before any insights from observational patient level studies can be collected and utilised, we need to ensure that a positive benefit-risk balance has been established in sufficiently powered clinical studies (144) as illustrated by the case of olaratumab. Greater funding for research into biomarkers and pharmacogenomics might also help ensure that situations such as olaratumab are less likely to occur in the future by increasing the predictability of the effects of new medicines on certain cancers and their different stages. However, this has to be balanced against current long time periods in Europe between patent filing and EMA approval which can be detrimental to patients.

Overall, we believe that the main priority should remain having data from phase III clinical trials before the submission of applications for marketing authorisation. If this is considered very difficult, and the medicinal product has the clear potential of addressing current unmet need, it is preferable to ensure that any clinical 
benefits seen early in the development of new medicines are confirmed by alternative trial designs that allow robust testing while ensuring patient access to active treatments, rather than granting early access for new medicines with incomplete documentation of their value, and assessing effectiveness in observational settings (101). These concerns are based on research showing that new medicines do not always deliver value to health care systems in practice, especially if such monies are taken from existing funds in other disease areas where they could have been used to fund proven effective treatments $(16,107,145)$. This is changing in England with funding for new cancer medicines now linked to MEAs coupled with an agreement of patient level data to be collected to aid future decision making (146). However, there are concerns regarding the quality and extent of patient level data that can currently routinely be collected in England to make robust decisions.

\section{Conclusions}

While the potential benefits of early access to patients in areas of high unmet medical need are recognized, there are important limitations derived from the impact of introducing and funding new medicines based on initial data to be confirmed during early clinical use. Patients may receive an ineffective treatment and suffer from adverse effects. In addition, in Europe and possibly other countries, expenditures for new cancer medicines are necessarily divested from other treatments that may have improved health gain.

As conditional authorisation can be challenging to reverse, and because there are potentially greater adverse effects of new medicines in clinical practice coupled with opportunity costs, it seems reasonable to reconsider current models for marketing authorisation, reimbursement and funding decisions, in favour of other mechanisms that may allow access for individual patients while robust evidence is being developed. This means that regulators should whenever possible oblige marketing authorisation holders to perform relevant clinical trials even if preliminary results indicate good efficacy, and manage the early access for individual patients through non-commercial approaches where companies do share the risk and are in charge of prospectively collecting data through research protocols. Olaratumab has once again illustrated why for regular marketing authorisations it should be systematically required to confirm the results of early clinical trials before granting commercial access to new drugs (147).

It also seems imperative that there should be closer collaboration between regulators, pharmaceutical companies and payers to enhance rapid and controlled confirmatory results. These should be obtained in a safe and fair way, with the minimum patient exposure required to achieve robust evidence, along with systems for controlled early access and new avenues for funding for instance new cancer medicines. It is recommended to have greater co-operation between countries regarding the collection of data in routine clinical care, more transparency over potential prices, discussions regarding what constitutes additional 'value' for new medicines and unmet medical need and, most importantly, the need for pharmaceutical companies to help fund the generation of information to fulfil any obligation for conditional marketing authorisation. Ongoing initiatives such as the formation of regional co-operations between European countries $(148,149)$ and activities to strengthen payer's legal expertise and negotiating skills, as suggested by the World Health Organization $(6,151)$ should also help in this regard. 


\section{Compliance with ethical standards}

There was no funding for this study. A number of the co-authors are employed by health authorities or are advisers to them. CP, CZ, JT, MO, CN, PVB, ME, RCH, JG, AT, APM, TM, AN, SC, GS, TB, CCR, IM, MB, JF, REM and BG have no other conflicts of interest to declare. Steven Simoens was a speaker at the European Digestive Oncology Research Forum funded by Lilly and participated in an advisory board on sustainability of cancer care funded by Hexal.

\section{Author contribution}

$\mathrm{CP}, \mathrm{CZ}, \mathrm{JT}$ and MO developed the initial concept and undertook the initial draft. All authors contributed to subsequent drafts based on their experience. All authors approved the submitted paper.

\section{References}

1. OECD. Health at a Glance 2017 - OECD Indicators. Available at URL: http://www.oecdilibrary.org/docserver/download/8117301e.pdf?expires=1521185400\&id=id\&accname=guest\&check sum=44B782D624C84AA214F8FDD3E46DADD6.

2. Arzneiverordnungs-Report 2018. Edited by Schwabe U, Paffrath D , Ludwig W-D and Klauber J. Available at URL: https://www.bookdepository.com/Arzneiverordnungs-Report-2018-UlrichSchwabe/9783662573853

3. Godman B, Malmstrom RE, Diogene E, Gray A, Jayathissa S, Timoney A, et al. Are new models needed to optimize the utilization of new medicines to sustain healthcare systems? Expert review of clinical pharmacology. 2015;8(1):77-94.

4. Malmstrom RE, Godman BB, Diogene E, Baumgartel C, Bennie M, Bishop I, et al. Dabigatran a case history demonstrating the need for comprehensive approaches to optimize the use of new drugs. Frontiers in pharmacology. 2013;4:39.

5. Godman B, Bucsics A, Vella Bonanno P, Oortwijn W, Rothe CC, Ferrario A, et al. Barriers for Access to New Medicines: Searching for the Balance Between Rising Costs and Limited Budgets. Front Public Health. 2018;6:328.

6. WHO. Access to new medicines in Europe: technical review of policy initiatives and opportunities for collaboration and research. Available at URL: http://www.euro.who.int/ data/assets/pdf file/0008/306179/Access-new-medicines-TR-PIOcollaboration-research.pdf?ua=1

7. Kelly RJ, Smith TJ. Delivering maximum clinical benefit at an affordable price: engaging stakeholders in cancer care. The Lancet Oncology. 2014;15(3):e112-8.

8. Chalkidou K, Marquez P, Dhillon PK, Teerawattananon Y, Anothaisintawee T, Gadelha CA, et al. Evidence-informed frameworks for cost-effective cancer care and prevention in low, middle, and high-income countries. The Lancet Oncology. 2014;15(3):e119-31.

9. Bray F, Ferlay J, Soerjomataram I, Siegel RL, Torre LA, Jemal A. Global cancer statistics 2018: GLOBOCAN estimates of incidence and mortality worldwide for 36 cancers in 185 countries. CA: a cancer journal for clinicians. 2018;68(6):394-424.

10. Howard DH, Bach P, Berndt ER, Conti RM. Pricing in the Market for Anticancer Drugs. Journal of Economic Perspectives. 2015;29(1):139-62.

11. Godman B, Wild C, Haycox A. Patent expiry and costs for anti-cancer medicines for clinical use. Generics and Biosimilars Initiative Journal 2017;6(3):105-6.

12. Kantarjian HM, Fojo T, Mathisen M, Zwelling LA. Cancer drugs in the United States: Justum Pretium--the just price. Journal of clinical oncology. 2013;31(28):3600-4.

13. Cohen D. Cancer drugs: high price, uncertain value. BMJ. 2017;359:j4543. 
14. Grössmann N, Wild C. Between January 2009 and April 2016, 134 novel anticancer therapies were approved: what is the level of knowledge concerning the clinical benefit at the time of approval? ESMO Open. 2017;1:e000125. doi:10.1136/ esmoopen-2016-000125.

15. Dusetzina SB. Drug Pricing Trends for Orally Administered Anticancer Medications Reimbursed by Commercial Health Plans, 2000-2014. JAMA oncology. 2016;2(7):960-1.

16. Haycox A. Why Cancer? PharmacoEconomics. 2016;34(7):625-7.

17. Gyawali B, Sullivan R. Economics of Cancer Medicines: For Whose Benefit? The New bioethics. 2017;23(1):95-104.

18. Luzzatto L, Hyry HI, Schieppati A, Costa E, Simoens S, Schaefer F, et al. Outrageous prices of orphan drugs: a call for collaboration. Lancet. 2018.

19. Godman B, Oortwijn W, de Waure C, Mosca I, Puggina A, Specchia ML et al. Links between Pharmaceutical R\&D Models and Access to Affordable Medicines. A Study for the ENVI COMMITTEE. Available

at

URL: http://www.europarl.europa.eu/RegData/etudes/STUD/2016/587321/IPOL STU(2016)587321 EN.p df.

20. Simoens S, Picavet E, Dooms M, Cassiman D, Morel T. Cost-effectiveness assessment of orphan drugs: a scientific and political conundrum. Applied health economics and health policy. 2013;11(1):1-3.

21. Cohen JP, Felix A. Are payers treating orphan drugs differently? Journal of Market Access \& Health Policy. 2014;2(1):23513.

22. Godman B, Campbell S, Suh HS, Finlayson AE, Bennie M, Gustafsson LL. Ongoing Measures to Enhance Prescribing Efficiency Across Europe: Implications for Other Countries. J Health Tech Assess 2013;1(27-42).

23. Dolgin E. Bringing down the cost of cancer treatment. Nature. 2018;555(7695):S26-s9.

24. IQVIA Institute for Human Data Science. Global Oncology Trends 2018. Available at URL: https://www.iqvia.com/institute/reports/global-oncology-trends-2018.

25. IMS Institute for Healthcare Informatics. Global Oncology Trend Report. A Review of 2015 and Outlook to 2020. June 2016. Available at URL: https://www.scribd.com/document/323179495/IMSHInstitute-Global-Oncology-Trend-2015-2020-Report.

26. The Lancet. GLOBOCAN 2018: counting the toll of cancer. Lancet. 2018;392(10152):985.

27. Durkee BY, Qian Y, Pollom EL, King MT, Dudley SA, Shaffer JL, et al. Cost-Effectiveness of Pertuzumab in Human Epidermal Growth Factor Receptor 2-Positive Metastatic Breast Cancer. Journal of clinical oncology : official journal of the American Society of Clinical Oncology. 2016;34(9):902-9.

28. Hoen Et. ACCESS TO CANCER TREATMENT. A study of medicine pricing issues with recommendations for improving access to cancer medication. Available at URL: http://apps.who.int/medicinedocs/documents/s21758en/s21758en.pdf

29. Hill A, Gotham D, Fortunak J, Meldrum J, Erbacher I, Martin M, et al. Target prices for mass production of tyrosine kinase inhibitors for global cancer treatment. BMJ open. 2016;6(1):e009586.

30. Hill A, Redd C, Gotham D, Erbacher I, Meldrum J, Harada R. Estimated generic prices of cancer medicines deemed cost-ineffective in England: a cost estimation analysis. BMJ open. 2017;7(1):e011965.

31. WHO Fair Pricing . INFORMAL ADVISORY GROUP MEETING. WHO Headquarters, Geneva 22 $24 \quad$ November $2016 . \quad$ Available at

https://www.who.int/medicines/access/fair pricing/report fair pricing-forumlGmeeting.pdf?ua=1.

32. Barber M, Gotham D, Hill A. Potential price reductions for cancer medicines on the WHO Essential Medicines List. Avaiable at URL: http://apps.who.int/medicinedocs/documents/s23154en/s23154en.pdf.

33. Campbell JD, Kalo Z. Fair global drug pricing. Expert review of pharmacoeconomics \& outcomes research. 2018;18(6):581-3. 
34. Vian T, Kohler JC, Forte G, Dimancesco D. Promoting transparency, accountability, and access through a multi-stakeholder initiative: lessons from the medicines transparency alliance. J Pharm Policy Pract. 2017;10:18.

35. Wilking N, Lopes G, Meier K, Simoens S, van Harten W, Vulto A. Can we Continue to Afford Access to Cancer Treatment? European Oncology \& Haematology,. 2017;13(2):114-9.

36. E. Sagonowsky. AbbVie's massive Humira discounts are stifling Netherlands biosimilars: report. 2019. Available at URL: https://www.fiercepharma.com/pharma/abbvie-stifling-humirabiosim-competition-massive-discounting-dutch-report.

37. Kaplan W, Wirtz V, Mantel-Teeuwisse A, Stolk P, Duthey P, Laing R. Priority Medicines for Europe and the World. 2013 Update. Available at URL: http://www.who.int/medicines/areas/priority medicines/MasterDocJune28 FINAL Web.pdf

38. Makady A, van Veelen A, de Boer A, Hillege $\mathrm{H}$, Klungel $\mathrm{OH}$, Goettsch W. Implementing managed entry agreements in practice: The Dutch reality check. Health policy. 2019;123(3):267-74.

39. Banzi R, Gerardi C, Bertele V, Garattini S. Approvals of drugs with uncertain benefit-risk profiles in Europe. European journal of internal medicine. 2015;26(8):572-84.

40. Hawkes N. Specialists attack drug agency's fast track approval scheme. BMJ. 2016;353:i3060.

41. Ermisch M, Bucsics A, Vella Bonanno P, Arickx F, Bybau A, Bochenek T, et al. Payers' Views of the Changes Arising through the Possible Adoption of Adaptive Pathways. Frontiers in pharmacology. 2016;7:305.

42. Scavone C, di Mauro G, Mascolo A, Berrino L, Rossi F, Capuano A. The New Paradigms in Clinical Research: From Early Access Programs to the Novel Therapeutic Approaches for Unmet Medical Needs. Frontiers in pharmacology. 2019;10:111.

43. Leyens L, Brand A. Early Patient Access to Medicines: Health Technology Assessment Bodies Need to Catch Up with New Marketing Authorization Methods. Public health genomics. 2016;19(3):187-91.

44. Cole A, Cubi-Molla P, Pollard J, Sim D, Sullivan R, Sussex J, Lorgelly P. Making Outcome-Based Payment a Reality in the NHS. 2019. Available at URL: file://C:/Users/mail/Downloads/Cole\%20et\%20al.\%20Making\%200utcome-

Based\%20Payment\%20a\%20Reality\%20in\%20the\%20NHS.pdf.

45. European Medicines Agency. PRIME: priority medicines. 2019. Available at URL: https://www.ema.europa.eu/en/human-regulatory/research-development/prime-prioritymedicines

46. European Medicines Agency. Adaptive Pathways. Available at URL: https://www.ema.europa.eu/en/human-regulatory/research-development/adaptive-pathways.

47. Grignolo A, Pretorius S. Phase III Trial Failures, Costly But Preventable. Applied Clinical Trials. 2016. Available at URL: https://www.parexel.com/application/files previous/5014/7274/5573/ACT Article.pdf.

48. Amiri-Kordestani L, Fojo T. Why do phase III clinical trials in oncology fail so often? Journal of the National Cancer Institute. 2012;104(8):568-9.

49. Gyawali B, Addeo A. Negative phase 3 randomized controlled trials: Why cancer drugs fail the last barrier? Int J Cancer. 2018;143(8):2079-81.

50. Walter RB, Appelbaum FR, Tallman MS, Weiss NS, Larson RA, Estey EH. Shortcomings in the clinical evaluation of new drugs: acute myeloid leukemia as paradigm. Blood. 2010;116(14):2420-8.

51. Jonker DJ, Nott L, Yoshino T, Gill S, Shapiro J, Ohtsu A, et al. Napabucasin versus placebo in refractory advanced colorectal cancer: a randomised phase 3 trial. The lancet Gastroenterology \& hepatology. 2018;3(4):263-70.

52. Prasad V, De Jesus K, Mailankody S. The high price of anticancer drugs: origins, implications, barriers, solutions. Nature reviews Clinical oncology. 2017;14(6):381-90.

53. Joppi R, Cinconze E, Mezzalira L, Pase D, Poggiani C, Rossi E, et al. Hospitalized patients with atrial fibrillation compared to those included in recent trials on novel oral anticoagulants: a population-based study. European journal of internal medicine. 2013;24(4):318-23. 
54. Bouvy JC, Sapede C, Garner S. Managed Entry Agreements for Pharmaceuticals in the Context of Adaptive Pathways in Europe. Frontiers in pharmacology. 2018;9:280-.

55. Ioannidis JPA. What Have We (Not) Learnt from Millions of Scientific Papers with P Values? The American Statistician. 2019;73(sup1):20-5.

56. Godman B, Wettermark B, van Woerkom M, Fraeyman J, Alvarez-Madrazo S, Berg C, et al. Multiple policies to enhance prescribing efficiency for established medicines in Europe with a particular focus on demand-side measures: findings and future implications. Frontiers in pharmacology. 2014;5:106.

57. Moorkens E, Vulto AG, Huys I, Dylst P, Godman B, Keuerleber S, et al. Policies for biosimilar uptake in Europe: An overview. PloS one. 2017;12(12):e0190147.

58. Dylst $P$, Vulto $A$, Simoens $S$. Demand-side policies to encourage the use of generic medicines: an overview. Expert review of pharmacoeconomics \& outcomes research. 2013;13(1):59-72.

59. Matusewicz W, Godman B, Pedersen HB, Furst J, Gulbinovic J, Mack A, et al. Improving the managed introduction of new medicines: sharing experiences to aid authorities across Europe. Expert review of pharmacoeconomics \& outcomes research. 2015;15(5):755-8.

60. Godman B, Malmstrom RE, Diogene E, Jayathissa S, McTaggart S, Cars T, et al. Dabigatran - a continuing exemplar case history demonstrating the need for comprehensive models to optimize the utilization of new drugs. Frontiers in pharmacology. 2014;5:109.

61. Eriksson I, Wettermark B, Persson M, Edstrom M, Godman B, Lindhe A, et al. The Early Awareness and Alert System in Sweden: History and Current Status. Frontiers in pharmacology. 2017;8:674.

62. Wettermark B, Godman B, Eriksson C, van Ganse E, Garattini S, Joppi R et al. Einführung neuer Arzneimittel in europäische Gesundheitssysteme (Introduction of new medicines into European healthcare systems). GGW. 2010;10(3):24 - 34 (Available at URL: https://www.wido.de/fileadmin/wido/downloads/pdf ggw/wido ggw aufs3 0710.pdf).

63. Kemp-Casey A, Pratt N, Ramsay E, Roughead EE. Using Post-market Utilisation Analysis to Support Medicines Pricing Policy: An Australian Case Study of Aflibercept and Ranibizumab Use. Applied health economics and health policy. 2019;17(3):411-7.

64. Garrison LP, Towse A. Value-Based Pricing and Reimbursement in Personalised Healthcare: Introduction to the Basic Health Economics. Journal of Personalized Medicine. 2017;7(3):10.

65. Garner S, Rintoul A, Hill SR. Value-Based Pricing: L'Enfant Terrible? PharmacoEconomics. 2018;36(1):5-6.

66. MOCA. Process on Corporate Social Responsibility in the Field of Pharmaceuticals Platform on Access to Medicines in Europe Working Group on Mechanism of Coordinated Access to Orphan Medicinal Products (MoCA-OMP). Available at URL: http://download2.eurordis.org.s3.amazonaws.com/moca/history/WG\%20MoCA-

OMP\%20Transparent\%20Value\%20Framework.pdf.

67. Seixas BV, Dionne F, Conte T, Mitton C. Assessing value in health care: using an interpretive classification system to understand existing practices based on a systematic review. BMC health services research. 2019;19(1):560.

68. Ferrario A, Kanavos P. Managed entry agreements for pharmaceuticals: the European experience. EMiNet, Brussels, Belgium. 2013. Available at URL: http://eprints.Ise.ac.uk/50513/

69. Ferrario A, Arāja D, Bochenek T, Čatić T, Dankó D, Dimitrova $M$, et al. The Implementation of Managed Entry Agreements in Central and Eastern Europe: Findings and Implications. PharmacoEconomics. 2017;35(12):1271-85.

70. Pauwels K, Huys I, Vogler S, Casteels M, Simoens S. Managed Entry Agreements for Oncology Drugs: Lessons from the European Experience to Inform the Future. Frontiers in pharmacology. 2017;8:171.

71. Carlson JJ, Chen S, Garrison LP, Jr. Performance-Based Risk-Sharing Arrangements: An Updated International Review. PharmacoEconomics. 2017;35(10):1063-72. 
72. Piatkiewicz TJ, Traulsen JM, Holm-Larsen T. Risk-Sharing Agreements in the EU: A Systematic Review of Major Trends. PharmacoEconomics - open. 2018;2(2):109-23.

73. Nazareth T, Ko JJ, Sasane R, Frois C, Carpenter S, Demean S, et al. Outcomes-Based Contracting Experience: Research Findings from U.S. and European Stakeholders. Journal of managed care \& specialty pharmacy. 2017;23(10):1018-26.

74. Morel T, Arickx F, Befrits G, Siviero P, van der Meijden C, Xoxi E, et al. Reconciling uncertainty of costs and outcomes with the need for access to orphan medicinal products: a comparative study of managed entry agreements across seven European countries. Orphanet journal of rare diseases. 2013;8:198.

75. MAP BioPharm. AIFA announces funding of CAR-T cell therapy using new reimbursement approach. 2019. Available at URL: https://mapbiopharma.com/2019/08/aifa-announces-funding-ofcar-t-cell-therapy-using-new-reimbursement-approach/.

76. Ferguson JS, Summerhayes M, Masters S, Schey S, Smith IE. New treatments for advanced cancer: an approach to prioritization. Br J Cancer. 2000;83(10):1268-73.

77. Wild C, Grossmann N, Bonanno PV, Bucsics A, Furst J, Garuoliene K, et al. Utilisation of the ESMO-MCBS in practice of HTA. Annals of oncology. 2016;27(11):2134-6.

78. Lopes G, Vulto A, Wilking N, van Harten W, Meier K, Simoens S. Potential Solutions for Sustaining the Costs of Cancer Drugs. European Oncology \& Haematology. 2017;13(2):102-7.

79. Garattini L, Curto A. Performance-Based Agreements in Italy: 'Trendy Outcomes' or Mere Illusions? PharmacoEconomics. 2016;34(10):967-9.

80. Goble JA, Ung B, van Boemmel-Wegmann S, Navarro RP, Parece A. Performance-Based RiskSharing Arrangements: U.S. Payer Experience. Journal of managed care \& specialty pharmacy. 2017;23(10):1042-52.

81. Yu JS, Chin L, Oh J, Farias J. Performance-Based Risk-Sharing Arrangements for Pharmaceutical Products in the United States: A Systematic Review. Journal of managed care \& specialty pharmacy. 2017;23(10):1028-40.

82. Makady A, van Acker S, Nijmeijer H, de Boer A, Hillege H, Klungel O, et al. Conditional Financing of Drugs in the Netherlands: Past, Present, and Future-Results From Stakeholder Interviews. Value in health. 2019;22(4):399-407.

83. Davis $C$, Lexchin J, Jefferson $T$, Gotzsche $P$, McKee M. "Adaptive pathways" to drug authorisation: adapting to industry? BMJ (Clinical research ed). 2016;354:i4437.

84. Garattini L, Curto A, van de Vooren K. Do the current performance-based schemes in Italy really work? "Success fee": a novel measure for cost-containment of drug expenditure. Value in health. 2015;18(2):352.

85. Navarria A, Drago V, Gozzo L, Longo L, Mansueto S, Pignataro G, et al. Do the current performance-based schemes in Italy really work? "Success fee": a novel measure for cost-containment of drug expenditure. Value in health. 2015;18(1):131-6.

86. Columbus G. Olaratumab Combination Misses OS Endpoint for Sarcoma in Phase III Trial. 2019. Available at URL: https://www.targetedonc.com/news/olaratumab-combination-misses-os-endpointfor-sarcoma-in-phase-iii-trial.

87. Lilly USA. Lilly Reports Results of Phase 3 Soft Tissue Sarcoma Study of LARTRUVO ${ }^{\circledR}$. Jan 18th 2019. Available at URL: https://investor.lilly.com/news-releases/news-release-details/lilly-reportsresults-phase-3-soft-tissue-sarcoma-study.

88. Vella Bonanno P, Ermisch M, Godman B, Martin AP, Van Den Bergh J, Bezmelnitsyna L, et al. Adaptive Pathways: Possible Next Steps for Payers in Preparation for Their Potential Implementation. Frontiers in pharmacology. 2017;8:497.

89. Lilly. Lartruvo: Summary of Product Characteristics. Available at URL: https://www.ema.europa.eu/documents/product-information/lartruvo-epar-productinformation en.pdf. 
90. Tap WD, Jones RL, Van Tine BA, Chmielowski B, Elias AD, Adkins D, et al. Olaratumab and doxorubicin versus doxorubicin alone for treatment of soft-tissue sarcoma: an open-label phase $1 \mathrm{~b}$ and randomised phase 2 trial. Lancet. 2016;388(10043):488-97.

91. EMA. EPAR Lartruvo - International non-proprietary name: olaratumab - Assessment report. September 2016. Available at URL: https://www.ema.europa.eu/en/documents/assessmentreport/lartruvo-epar-public-assessment-report en.pdf.

92. European Medicines Agency. Lartruvo. 2016. Available at: https://www.ema.europa.eu/en/documents/overview/lartruvo-epar-summary-public en.pdf.

93. Food and Drug Administration. FDA News Release: FDA grants accelerated approval to new treatment for advanced soft tissue sarcoma. 2016. Available at URL: https://www.fda.gov/NewsEvents/Newsroom/PressAnnouncements/ucm525878.htm)

94. Tap WD, Wagner AJ, Papai Z, Ganjoo KN, Yen C-C, Schoffski P, et al. ANNOUNCE: A randomized, placebo (PBO)-controlled, double-blind, phase (Ph) III trial of doxorubicin (dox) + olaratumab versus dox + PBO in patients (pts) with advanced soft tissue sarcomas (STS). Journal of Clinical Oncology. 2019;37(18_suppl):LBA3-LBA.

95. European Medicines Agency. No new patients should start treatment with Lartruvo after study shows cancer medicine does not prolong life. 2019. Available at: https://www.ema.europa.eu/en/news/no-new-patients-should-start-treatment-lartruvo-afterstudy-shows-cancer-medicine-does-not-prolong.

96. Food and Drug Administration. FDA News Release: FDA grants accelerated approval to new treatment for advanced soft tissue sarcoma. 2019. Available at URL: https://www.fda.gov/NewsEvents/Newsroom/PressAnnouncements/ucm525878.htm.

97. Eichler HG, Oye K, Baird LG, Abadie E, Brown J, Drum CL, et al. Adaptive licensing: taking the next step in the evolution of drug approval. Clinical pharmacology and therapeutics. 2012;91(3):42637.

98. Baird LG, Banken R, Eichler HG, Kristensen FB, Lee DK, Lim JC, et al. Accelerated access to innovative medicines for patients in need. Clinical pharmacology and therapeutics. 2014;96(5):55971.

99. Bouvy JC, Jonsson P, Longson C, Crabb N, Garner S. Health Technology Assessment in the Context of Adaptive Pathways for Medicines in Europe: Challenges and Opportunities. Clinical pharmacology and therapeutics. 2016;100(6):594-7.

100. Barrett A, Roques T, Small M, Smith RD. How much will Herceptin really cost? BMJ (Clinical research ed). 2006;333(7578):1118-20.

101. Pontes C, Fontanet JM, Vives R, Sancho A, Gomez-Valent M, Rios J, et al. Evidence supporting regulatory-decision making on orphan medicinal products authorisation in Europe: methodological uncertainties. Orphanet journal of rare diseases. 2018;13(1):206.

102. Godman B, Finlayson AE, Cheema PK, Zebedin-Brandl E, Gutierrez-lbarluzea I, Jones J, et al. Personalizing health care: feasibility and future implications. BMC medicine. 2013;11:179.

103. FDA. FDA approves larotrectinib for solid tumors with NTRK gene fusions. 2018. Available at URL: https://www.fda.gov/drugs/fda-approves-larotrectinib-solid-tumors-ntrk-gene-fusions-0.

104. Davis C, Naci H, Gurpinar E, Poplavska E, Pinto A, Aggarwal A. Availability of evidence of benefits on overall survival and quality of life of cancer drugs approved by European Medicines Agency: retrospective cohort study of drug approvals 2009-13. BMJ. 2017;359:j4530.

105. European Medicines Agency. Conditional marketing authorisation. EMA/471951/2016. Available at URL: https://www.ema.europa.eu/documents/report/conditional-marketingauthorisation-report-ten-years-experience-european-medicines-agency en.pdf.

106. Tao D, Schott S, Prasad V. The Tradeoff of Cancer Drug Regulatory Policy: Faster Approvals for One Means Less Knowledge for Another. The American journal of medicine. 2019;132(3):e509-e11.

107. Editorial. New 50 million pound cancer fund already intellectually bankrupt. Lancet. 2010;376(9739):389. 
108. European Medicines Agency. Points to consider on application with 1. meta-analyses; 2 . one pivotal study . CPMP/EWP/2330/99. 2001. Available at URL: https://www.ema.europa.eu/en/application-1-meta-analyses-2-one-pivotal-study.

109. Hemmings R. An overview of statistical and regulatory issues in the planning, analysis, and interpretation of subgroup analyses in confirmatory clinical trials. Journal of biopharmaceutical statistics. 2014;24(1):4-18.

110. Frisk P, Aggefors K, Cars T, Feltelius N, Loov SA, Wettermark B, et al. Introduction of the second-generation direct-acting antivirals (DAAs) in chronic hepatitis C: a register-based study in Sweden. European journal of clinical pharmacology. 2018;74(7):971-8.

111. Mueller T, Alvarez-Madrazo S, Robertson C, Wu O, Bennie M. Comparative safety and effectiveness of direct oral anticoagulants in patients with atrial fibrillation in clinical practice in Scotland. British journal of clinical pharmacology. 2019;85(2):422-31.

112. Xoxi E, Tomino C, De Nigro L, Pani L. The Italian post-marketing registries. Pharmaceutical Programming 2012; 5: 57-60.

113. Wallach JD, Ciani O, Pease AM, Gonsalves GS, Krumholz HM, Taylor RS, et al. Comparison of treatment effect sizes from pivotal and postapproval trials of novel therapeutics approved by the FDA based on surrogate markers of disease: a meta-epidemiological study. BMC medicine. 2018;16(1):45-

114. Zeitoun JD, Baron G, Vivot A, Atal I, Downing NS, Ross JS, et al. Post-marketing research and its outcome for novel anticancer agents approved by both the FDA and EMA between 2005 and 2010: A cross-sectional study. Int J Cancer. 2018;142(2):414-23.

115. KCE. HOW TO IMPROVE THE BELGIAN PROCESS FOR MANAGED ENTRY AGREEMENTS? 2017. Available

at

URL:

https://kce.fgov.be/sites/default/files/atoms/files/Download\%20the\%20synthesis\%20in\%20English \%20\%2840\%20p.\%29.pdf.

116. European Commission. INNOVATIVE PAYMENT MODELS FOR HIGH-COST INNOVATIVE MEDICINES. Available at URL: https://ec.europa.eu/health/expert panel/sites/expertpanel/files/docsdir/opinion innovative medi cines en.pdf.

117. European Commission. Council Directive 89/105/EEC of 21 December 1988 relating to the transparency of measures regulating the pricing of medicinal products for human use and their inclusion in the scope of national health insurance systems. 1989. Available at URL: https://ec.europa.eu/health/sites/health/files/files/eudralex/vol-

1/dir 1989 105/dir 1989105 en.pdf.

118. Vogler S, Paris V, Ferrario A, Wirtz VJ, de Joncheere K, Schneider P, et al. How Can Pricing and Reimbursement Policies Improve Affordable Access to Medicines? Lessons Learned from European Countries. Applied health economics and health policy. 2017;15(3):307-21.

119. Vogler S, Paris V, Panteli D. European Observatory Policy Briefs. In: Richardson E, Palm W, Mossialos E, editors. Ensuring access to medicines: How to redesign pricing, reimbursement and procurement? Copenhagen (Denmark): European Observatory on Health Systems and Policies

(c) World Health Organization 2018 (acting as the host organization for, and secretariat of, the European Observatory on Health Systems and Policies). 2018.

120. UN News. Greater transparency, fairer prices for medicines 'a global human rights issue', says UN health agency. 2019. Available at URL: https://news.un.org/en/story/2019/04/1036651.

121. United Nations. UNITED NATIONS SECRETARY-GENERAL'S HIGH-LEVEL PANEL ON ACCESS TO MEDICINE. 2016. Available at URL https://static1.squarespace.com/static/562094dee4b0d00c1a3ef761/t/57d9c6ebf5e231b2f02cd3d4 /1473890031320/UNSG+HLP+Report+FINAL+12+Sept+2016.pdf.

122. EFPIA. Value of medicines. Section 4 - Why are the net prices of medicines not more transparent? 2019. Available at URL: https://www.efpia.eu/about-medicines/use-ofmedicines/value-of-medicines/. 
123. Turajlic S, Sottoriva A, Graham T, Swanton C. Resolving genetic heterogeneity in cancer. Nature reviews Genetics. 2019.

124. Antonanzas F, Rodriguez-Ibeas R, Juarez-Castello CA. Personalized Medicine and Pay for Performance: Should Pharmaceutical Firms be Fully Penalized when Treatment Fails? PharmacoEconomics. 2018;36(7):733-43.

125. Kesselheim AS, Myers JA, Solomon DH, Winkelmayer WC, Levin R, Avorn J. The prevalence and cost of unapproved uses of top-selling orphan drugs. PloS one. 2012;7(2):e31894.

126. The price of drugs for chronic myeloid leukemia $(C M L)$ is a reflection of the unsustainable prices of cancer drugs: from the perspective of a large group of CML experts. Blood. 2013;121(22):4439-42.

127. Pegram MD, Bondarenko I, Zorzetto MMC, Hingmire S, Iwase H, Krivorotko PV, et al. PF05280014 (a trastuzumab biosimilar) plus paclitaxel compared with reference trastuzumab plus paclitaxel for HER2-positive metastatic breast cancer: a randomised, double-blind study. Br J Cancer. 2019;120(2):172-82.

128. Taylor P. Herceptin. FiercePharma. 2017. Available at URL: https://www.fiercepharma.com/special-report/herceptin-2.

129. Genentech. Herceptin - trastuzumab - Prescribing information. 2019. Available at URL: https://www.herceptin.com/hcp/.

130. Workman P, Draetta GF, Schellens JH, Bernards R. How Much Longer Will We Put Up With $\$ 100,000$ Cancer Drugs? Cell. 2017;168(4):579-83.

131. KEl. Delinkage. Available at URL: http://delinkage.org/overview/.

132. Outterson K, Gopinathan U, Clift C, So AD, Morel CM, Rottingen JA. Delinking Investment in Antibiotic Research and Development from Sales Revenues: The Challenges of Transforming a Promising Idea into Reality. PLoS Med. 2016;13(6):e1002043.

133. Raaschou P, Simard JF, Asker Hagelberg C, Askling J. Rheumatoid arthritis, anti-tumour necrosis factor treatment, and risk of squamous cell and basal cell skin cancer: cohort study based on nationwide prospectively recorded data from Sweden. The BMJ. 2016;352:i262.

134. lannone F, Gremese E, Atzeni F, Biasi D, Botsios C, Cipriani P, et al. Longterm retention of tumor necrosis factor-alpha inhibitor therapy in a large italian cohort of patients with rheumatoid arthritis from the GISEA registry: an appraisal of predictors. The Journal of rheumatology. 2012;39(6):1179-84.

135. Garcia-Doval I, Cohen AD, Cazzaniga S, Feldhamer I, Addis A, Carretero G, et al. Risk of serious infections, cutaneous bacterial infections, and granulomatous infections in patients with psoriasis treated with anti-tumor necrosis factor agents versus classic therapies: Prospective meta-analysis of Psonet registries. Journal of the American Academy of Dermatology. 2017;76(2):299-308.e16.

136. Dos Santos JB, Almeida AM, Acurcio FA, de Oliveira Junior HA, Kakehasi AM, Guerra Junior AA, et al. Comparative effectiveness of adalimumab and etanercept for rheumatoid arthritis in the Brazilian Public Health System. Journal of comparative effectiveness research. 2016;5(6):539-49.

137. Blin P, Dureau-Pournin C, Cottin Y, Benichou J, Mismetti P, Abouelfath A, et al. Comparative effectiveness and safety of standard or reduced dose dabigatran versus rivaroxaban in non-valvular atrial fibrillation. Clinical pharmacology and therapeutics. 2018.

138. Maura G, Pariente A, Alla F, Billionnet C. Adherence with direct oral anticoagulants in nonvalvular atrial fibrillation new users and associated factors: a French nationwide cohort study. Pharmacoepidemiol Drug Saf. 2017;26(11):1367-77.

139. BertelsmannStiftung. SmartHealthSystems International comparison of digital strategies. 2018. Available at URL: https://www.bertelsmannstiftung.de/fileadmin/files/Projekte/Der digitale Patient/VV SHS-Studie EN.pdf.

140. Pearson SD, Dreitlein WB, Towse A, Hampson G, Henshall C. A framework to guide the optimal development and use of real-world evidence for drug coverage and formulary decisions. Journal of comparative effectiveness research. 2018;7(12):1145-52. 
141. Blommestein HM, Franken MG, Uyl-de Groot CA. A practical guide for using registry data to inform decisions about the cost effectiveness of new cancer drugs: lessons learned from the PHAROS registry. PharmacoEconomics. 2015;33(6):551-60.

142. Mohseninejad L, van Gils C, Uyl-de Groot CA, Buskens E, Feenstra T. Evaluation of patient registries supporting reimbursement decisions: the case of oxaliplatin for treatment of stage III colon cancer. Value in health. 2015;18(1):84-90.

143. Fahr P, Buchanan J, Wordsworth S. A Review of the Challenges of Using Biomedical Big Data for Economic Evaluations of Precision Medicine. Applied health economics and health policy. 2019.

144. Sherman RE, Anderson SA, Dal Pan GJ, Gray GW, Gross T, Hunter NL, et al. Real-World Evidence - What Is It and What Can It Tell Us? N Engl J Med. 2016;375(23):2293-7.

145. Aggarwal A, Fojo T, Chamberlain C, Davis C, Sullivan R. Do patient access schemes for highcost cancer drugs deliver value to society?-lessons from the NHS Cancer Drugs Fund. Ann Oncol. 2017;28(8):1738-1750

146. NHS England. Appraisal and Funding of Cancer Drugs from July 2016 (including the new Cancer Drugs Fund). A new deal for patients, taxpayers and industry. 2016. Available at URL: https://www.england.nhs.uk/wp-content/uploads/2013/04/cdf-sop.pdf.

147. INTERNATIONAL CONFERENCE ON HARMONISATION OF TECHNICAL REQUIREMENTS FOR REGISTRATION OF PHARMACEUTICALS FOR HUMAN USE. ICH HARMONISED TRIPARTITE GUIDELINE E9. 1998. Available at URL: http://academy.gmp-compliance.org/guidemgr/files/E9 GUIDELINE.PDF. 148. KCE REPORT 283. HORIZON SCANNING FOR PHARMACEUTICALS: PROPOSAL FOR THE BENELUXA COLLABORATION. Available atURL: http://www.beneluxa.org/sites/beneluxa.org/files/2017-

07/Horizon\%20scanning ScientificReport full.pdf.

149. O'Mahony JF. Beneluxa: What are the Prospects for Collective Bargaining on Pharmaceutical Prices Given Diverse Health Technology Assessment Processes? PharmacoEconomics. 2019;37(5):62730.

150. Vella Bonanno P, Bucsics A, Simoens S, Martin AP, Oortwijn W, Gulbinovic J, et al. Proposal for a regulation on health technology assessment in Europe - opinions of policy makers, payers and academics from the field of HTA. Expert review of pharmacoeconomics \& outcomes research. 2019;19(3):251-61.

151. WHO Europe. MEDICINES REIMBURSEMENT POLICIES IN EUROPE. Available at URL: http://www.euro.who.int/ data/assets/pdf file/0011/376625/pharmaceutical-reimbursementeng.pdf?ua=1. 